\title{
Conhecimento fonológico e apropriação de róticos em inglês L2 por falantes nativos de português brasileiro
}

\author{
Thaïs Cristófaro Silva* \\ Universidade Federal de Minas Gerais \\ Belo Horizonte, MG, BR \\ Marco Aurélio Camargos ${ }^{* *}$ \\ Universidade Federal de Minas Gerais \\ Belo Horizonte, MG, BR
}

\begin{abstract}
Resumo
Este artigo discute a apropriação de róticos em inglês-L2 por falantes brasileiros. Os resultados obtidos indicam que a categoria dos róticos é rapidamente incorporada ao inglês-L2 de falantes brasileiros. Fatores como nível de proficiência, indivíduo (aprendiz) e item lexical têm impacto na apropriação da aproximante retroflexa. $\mathrm{O}$ fato da apropriação da aproximante retroflexa atingir rapidamente excelentes níveis em inglês-L2 de falantes brasileiros sugere que o ensino de pronúncia seja específico e não global. Baseado na perspectiva teórica fonológica dos Modelos Multirrepresentacionais (BYBEE, 2001, 2008, 2010; JOHNSON, 1997; PIERREHUMBERT, 2001, 2003) argumenta-se que o conhecimento gramatical é um construto dinâmico, entrelaçado por vários fatores linguísticos e não linguísticos.
\end{abstract}

Palavras-chave: Rótico; Aproximante Retroflexa; Teoria de Exemplares; Modelos Multirrepresentacionais

\section{Phonological knowledge of rhotics in English L2 of brazilian speakers}

\begin{abstract}
This article discusses the appropriation of rhotics in English-L2 spoken by Brazilian speakers. The results show that rhotics are quickly incorporated into the English-L2 speakers' production. A detailed examination of the data indicates that the following factors are relevant in the appropriation of retroflex approximant in English-L2: proficiency, the individual (learner) and the lexical item. The fact that the appropriation of the retroflex approximant quickly achieves excellent levels in English-L2 spoken by Brazilian speakers suggests that teaching of pronunciation is specific and not global. Based on Multirepresentational Models, it is argued that grammatical knowledge is a dynamic construct, interlaced by various linguistic and non-linguistic factors.
\end{abstract}

Keywords: Rhotic; Retroflex Approximant; Exemplar Models; Multirepresentational Models

\footnotetext{
* Thaïs Cristófaro Silva é professora Titular de Linguística na Universidade Federal de Minas Gerais. Coordena o Laboratório de Fonologia da UFMG onde são desenvolvidos projetos em Fonologia teórica com ênfase no desenvolvimento de mudanças sonoras, aquisição de língua materna e estrangeira e tecnologia da fala. E-mail: thaiscristofarosilva@ufmg.br

${ }^{* *}$ Marco Aurélio Camargos é mestre em Linguística pela UFMG. Atualmente é professor de inglês cujos interesses teóricos são relacionados aos desafios impostos ao ensino e aprendizado de pronúncia para falantes brasilerios de inglês. E-mail: marcoaurelio204@hotmail.com
} 


\section{Introdução}

Este artigo discute a apropriação de róticos em inglês-L2 de falantes brasileiros. ${ }^{1}$ Frequentemente, a literatura fonológica remete a fatores que apresentam dificuldades de aprendizagem para os estudantes de uma língua estrangeira. ${ }^{2}$ Pouco é discutido quanto aos fatores que, em princípio, não impõem desafios ao estudante de L2. Este artigo pretende ser uma contribuição para essa última perspectiva de investigação. Os resultados desta pesquisa apontam para o fato de que a aproximante retroflexa é rapidamente incorporada ao inglês-L2 por aprendizes de diferentes regiões geográficas, independente se na variedade de L1 ocorre ou não uma consoante aproximante retroflexa.

Visando compreender porque os falantes brasileiros utilizam adequadamente os róticos em inglês-L2, vamos explorar a relação entre conhecimento fonológico e organização lexical e a interação entre fatores linguísticos e não linguísticos na apropriação de L2. O conhecimento fonológico é compreendido como sendo de natureza procedimental, ou seja, o falante é capaz de fazer uso do conhecimento, mas não é capaz de explicitar como utilizou tal conhecimento (ANDERSON,1993). ${ }^{3}$ No estudo de caso analisado neste artigo o conhecimento fonológico está relacionado com a produção de róticos em L1 e L2.

Serão analisados dados de duas variedades regionais do PB. Uma destas variedades é falada em Belo Horizonte e a outra é falada em Lavras, ambos municípios do estado de Minas Gerais. Na variedade de Belo Horizonte o rótico que ocorre em final de sílaba é uma fricativa posterior - ['mah] mar - e na variedade de Lavras o rótico que ocorre em final de sílaba é uma aproximante retroflexa: ['mar] mar. Em início de sílaba o rótico é uma fricativa posterior nas duas variedade: ['hu.a. ${ }^{4}$ rua ou ['ka.hu] carro. Em encontros consonantais e entre vogais o tepe ocorre tanto em Belo Horizonte quanto em Lavras: ['pra.tu] prato e ['ka.ra] cara. Considerando-se as particularidades regionais quanto ao tipo de rótico que ocorre em final de sílaba formulamos a seguinte pergunta de pesquisa: Como se dá a apropriação da aproximante retroflexa por aprendizes brasileiros de inglês-L2, levando em consideração diferentes variedades dialetais? Para responder a esta pergunta realizamos um experimento que será discutido nas próximas páginas.

O referencial teórico é baseado nos Modelos Multirrepresentacionais (BYBEE, 2001, 2008, 2010; JOHNSON, 1997; PIERREHUMBERT, 2001, 2003), que têm como pressuposto principal que o sistema linguístico é construído a partir de eventos de uso. Considerando-se que falantes de Lavras fazem uso da aproximante retroflexa em final de sílaba e os falantes de Belo Horizonte não o fazem, os resultados desta pesquisa devem contribuir com o debate sobre o a relação entre eventos de uso e organização gramatical. Este artigo tem a seguinte organização: a próxima seção discute a distribuição dos róticos em português e no inglês. A terceira seção apresenta a fundamentação teórica. A quarta seção descreve a metodologia empregada neste estudo. A quinta seção discute os resultados obtidos e é seguida da conclusão e das referências bibliográficas.

\section{Os róticos em inglês e em português}

Lindau (1985) e Ladefoged \& Maddieson (1996) indicam que a classe de róticos é referida na literatura como 'sons de r.' O grupo dos róticos tende a se comportar fonologicamente de maneira semelhante, apresentando, sobretudo, características distribucionais comuns. Foneticamente, os róticos apresentam grande variabilidade articulatória, o que não permite agregá-los em uma única classe fonética (LINDAU, 1985; MAGNUSON, 2007). O consenso é de que os róticos são uma classe fonológica cujos sons têm associação com a letra 'r'. Os róticos no PB e no inglês têm distribuições distintas. No PB falado em Minas Gerais, os róticos agregam várias classes de sons: aproximantes retroflexas, fricativas e tepes com distribuição específica como ilustrado no Quadro 1:

\begin{tabular}{|l|l|l|l|}
\hline & Contexto & Fonética & Ortografia \\
\hline a. & $\begin{array}{l}\text { Pós-vocálica } \\
\text { em final de } \\
\text { palavra }\end{array}$ & ['mah] ['ma.I] & mar \\
\hline b. & $\begin{array}{l}\text { Pós-vocálica } \\
\text { seguida de } \\
\text { consoante }\end{array}$ & ['pah.ki] ['pa..ki] & parque \\
\hline
\end{tabular}




\begin{tabular}{|l|l|l|l|}
\hline c. & $\begin{array}{l}\text { Início de } \\
\text { sílaba e de } \\
\text { palavra }\end{array}$ & ['hu.a] & rua \\
\hline d. & $\begin{array}{l}\text { Início de sí- } \\
\text { laba precedido } \\
\text { de consoante }\end{array}$ & [is.ha. 'Ew] & Israel \\
\hline e. & $\begin{array}{l}\text { Início de sí- } \\
\text { laba precedido } \\
\text { de vogal }\end{array}$ & ['ka.hu] & carro \\
\hline f. & $\begin{array}{l}\text { Início de sí- } \\
\text { laba precedido } \\
\text { de vogal }\end{array}$ & ['ka.ru] & caro \\
\hline g. & $\begin{array}{l}\text { Encontro } \\
\text { consonantal }\end{array}$ & ['pra.tu] & prato \\
\hline
\end{tabular}

Quadro 1: Distribuição do rótico no PB falado em Minas Gerais

As linhas (a,b) do Quadro 1 ilustram que em posição pós-vocálica a fricativa glotal alterna com uma aproximante retroflexa. ${ }^{5} \mathrm{~A}$ alternância é atribuída a falares regionais. Em início de sílaba ocorre uma fricativa glotal (c-e) ou um tepe (f). Em encontros consonantais tautossilábicos ocorre sistematicamente um tepe: (g). Por outro lado, embora o rótico em inglês apresente variação, ele tende a ocorrer com bastante sistematicidade como uma aproximante retroflexa como ilustrado no Quadro 2.

\begin{tabular}{|l|l|l|l|l|l|}
\hline & Contexto & \multicolumn{2}{|l|}{ Fonética } & Ortografia & Glossa \\
\hline a. & $\begin{array}{l}\text { Pós-vocálica } \\
\text { em final de } \\
\text { palavra }\end{array}$ & ['ka:r] & ['ka:] & car & carro \\
\hline b. & $\begin{array}{l}\text { Pós-vocálica } \\
\text { seguida de } \\
\text { consoante }\end{array}$ & ['pa:rk] & ['pa:k] & park & parque \\
\hline c. & $\begin{array}{l}\text { Pós-vocálica } \\
\text { seguida de } \\
\text { vogal }\end{array}$ & ['ver.i] & very & muito \\
\hline d. & $\begin{array}{l}\text { Início de } \\
\text { palavra }\end{array}$ & ['red] & red & $\begin{array}{l}\text { ver- } \\
\text { melho }\end{array}$ \\
\hline e. & $\begin{array}{l}\text { Encontro } \\
\text { consonantal }\end{array}$ & ['kraI] & cry & choro \\
\hline
\end{tabular}

Quadro 2: Distribuição do rótico na língua inglesa

As linhas (a,b) do Quadro 2 ilustram contextos em que a aproximante retroflexa ocorre em posição pós- vocálica que coincide com o final da palavra (car 'carro') ou em posição pós-vocálica seguida de consoante (park 'parque') e o rótico pode ou não ser realizado dependendo da variedade regional. As variedades em que o rótico é pronunciado são denominadas róticas ( $3^{\mathrm{a}} \mathrm{co}$ luna no Quadro 2) e as variedades em que o rótico não é pronunciado são denominadas não-róticas ( $4^{\mathrm{a}}$ coluna no Quadro 2). ${ }^{7}$ Por outro lado, nos exemplos apresentados nas linhas (c-e), independentemente da variedade ser rótica ou não, a aproximante retroflexa tende a sempre pronunciada em inglês. ${ }^{8}$

Os contextos distribucionais apresentados nos Quadros 1 e 2 indicam que em posição pós-vocálica em final de palavra ou em posição pós-vocálica seguida de consoante uma aproximante retroflexa pode ocorrer tanto no inglês quanto no PB e apresentar variação. A variação é atribuída a falares regionais: no inglês a aproximante retroflexa alterna com seu cancelamento e no $\mathrm{PB}$ a aproximante retroflexa alterna com uma fricativa posterior. ${ }^{9}$ A próxima seção apresenta a fundamentação teórica desta pesquisa.

\section{Fundamentação teórica: Modelos Multirrepre- sentacionais}

Esta pesquisa tem como princípio teórico os Modelos Multirrepresentacionais que compreendem a Fonologia de Uso e Modelo de Redes (BYBEE, 2001, 2008, 2010) e a Teoria dos Exemplares (JOHNSON, 1997; PIERREHUMBERT, 2001, 2003). Os modelos de uso compartilham a ideia de que o sistema linguístico é construído a partir de eventos de uso, como apontam Barlow e Kemmer (2000).

Tendo em vista que o sistema linguístico emerge do uso real da língua, ou seja, da experiência que o falante tem com a língua, Bybee (2010) questiona se esses processos são específicos da linguagem ou se podem ser atribuídos a outros domínios da cognição. A autora aponta que processos cognitivos de domínios não-linguísticos podem também ser aplicados à linguagem. Os processos de domínio geral incluem: categorização, agrupamento (chunking), armazenamento de memória enriquecida e analogia. Destes processos o que nos interessa em particular é a categorização e com foco espe- 
cífico na categorização de róticos no PB e inglês-L2. A categorização é baseada em identidade e em similaridade. Assim, espera-se que sons similares em L1 e L2 sejam categorizados mais prontamente do que sons de L2 que são desconhecidos em L1. Esta observação decorre do uso ser relevante para a construção do conhecimento gramatical (BYBEE 2001, p. 8).

A Fonologia de Uso postula que um som qualquer tem forte relação com a organização gramatical, que o detalhe fonético é crucial na organização fonológica e que a organização lexical apresenta estreita relação com o conhecimento linguístico do falante (BYBEE, 2001, 2010). Alguns dos princípios básicos de um modelo baseado no uso, apontados por Bybee (2001, p.6), são: a experiência afeta representações; as representações mentais de objetos linguísticos têm as mesmas propriedades de representações mentais de outros objetos; a categorização é baseada em identidade e em similaridade; as generalizações em relação a formas não são separadas de representações, e sim, emergem a partir das formas; a organização lexical oferece generalizações e segmentações em vários níveis de abstração e generalização; o conhecimento gramatical representa conhecimento procedimental. ${ }^{10}$

No intuito de explicar como a experiência do falante é armazenada e categorizada, temos a Teoria de Exemplares (JOHNSON, 1997; PIERREHUMBERT, 2001, 2003) que, estando em consonância com a Fonologia de Uso, sugere que os falantes têm conhecimento fonético detalhado dos itens lexicais e que eles fazem uso de tal conhecimento. Os principais aspectos da Teoria de Exemplares importantes para o presente trabalho são: os sons são avaliados em contextos em que ocorrem, sendo a palavra o lócus de categorização e aspectos não linguísticos têm impacto na consolidação do conhecimento gramatical.

Segundo a Teoria de Exemplares, os itens lexicais são armazenados de acordo com a similaridade semântica e fonética, formando, assim, categorias, também conhecidas como feixe de exemplares. Portanto, palavras com alto grau de similaridade acústica e/ou articulatória são classificadas como membros de um mesmo feixe de exemplares.
Como apontam Bod e Cochran (2007), quando o falante se depara com certa palavra, ele armazena na memória informações fonéticas detalhadas assim como informações não-linguísticas relacionadas a essas palavras. Esse mesmo falante, ao se deparar com outra palavra a categoriza e armazena de acordo com a similaridade dos exemplares já presentes na memória. Portanto, as palavras podem ser categorizadas mais de uma vez, ao serem associadas a formas fonéticas diferentes. Dessa forma, a Teoria de Exemplares sugere que as informações linguísticas e não-linguísticas são capturadas em detalhes e armazenadas em feixes de exemplares.

Bybee (2008) aponta que a exposição e a prática por parte do aprendiz é essencial à aprendizagem, levando-o a um desenvolvimento melhor das estruturas cognitivas. Uma criança ao adquirir sua L1 está o tempo todo exposta à língua, ou seja, exposta a um meio natural para a aquisição. Por outro lado, um aprendiz de L2 tipicamente está exposto a um meio artificial, baseado, sobretudo, em estímulos do material didático e do professor, ou seja, ele está menos exposto à língua-alvo.

Outro aspecto de experiência do falante/aprendiz é a automatização, que diz respeito à repetição de formas e estruturas. Repetir sequências e padrões estruturais faz com que representações fiquem mais fortalecidas, sendo, portanto, fáceis de acessar (ELLIS, 2003; ROBINSON \& ELLIS, 2008). A repetição não é puramente simples e mecânica, como visto no behaviorismo, e sim atrelada ao uso e ao contexto. Em outras palavras, a repetição, ou seja, o fortalecimento da estrutura baseada no uso, torna-se uma ferramenta importante para aprender uma L2, uma vez que o uso dessa estrutura tem um impacto nas representações.

No que concerne ao presente estudo pretendemos avaliar se sons familiares em L1 são mais prontamente apropriados em L2. Para tal analisaremos a apropriação da aproximante retroflexa em inglês-L2 de falantes de Lavras (variedade que apresenta aproximantes retroflexas) e Belo Horizonte (variedade que não apresenta aproximantes retroflexas). A expectativa é que a partir de princípios de categorização a aproximante retroflexa seja apropriada em maiores índices por falantes de Lavras do que falantes de Belo Horizonte. 
Esta seção teve por objetivo apresentar os princípios teóricos dos Modelos Multirrepresentacionais que subsidiaram este estudo. Dada a teoria, retomamos a principal pergunta desta pesquisa: Como se dá a apropriação da aproximante retroflexa por aprendizes brasileiros de inglês-L2, levando em consideração diferentes variedades dialetais? Esta pergunta será respondida à luz dos pressupostos teóricos adotados e levará à formulação de outras questões que serão apontadas ao longo do artigo. A metodologia da pesquisa é descrita na próxima seção.

\section{Metodologia}

A pesquisa envolveu um experimento realizado com participantes das cidades de Belo Horizonte e de Lavras, ambas do estado de Minas Gerais. ${ }^{11}$ As duas cidades foram escolhidas por apresentarem diferentes róticos em posição pós-vocálica: Belo Horizonte apresenta tipicamente consoantes fricativas (CRISTÓFARO-SILVA, 1999) e Lavras apresenta tipicamente aproximantes retroflexas (BRANDÃO, 2007; RENNICKE, 2011). ${ }^{12}$ Para cada cidade foram selecionados 16 participantes, todos com curso superior em andamento. Todos os participantes eram do sexo masculino. Metade dos participantes tinha nível básico de proficiência em inglês e a outra metade tinha nível avançado de proficiência em inglês. ${ }^{13}$

Um total de 33 itens léxicos foi investigado: 13 itens léxicos do português e 20 itens léxicos do inglês. ${ }^{14}$ O experimento com itens léxicos do português foi realizado em sessão distinta do experimento com itens léxicos do inglês. Cada item léxico foi apresentado ao participante em tela de laptop, no formato de slide feito em Power Point. Foi dito ao participante que se tratava de um jogo de figuras para avaliação de conhecimento de vocabulário. Na tela do laptop, eram expostas duas figuras distintas e uma frase abaixo delas com uma lacuna em branco. O participante deveria escolher qual a figura que mais se adequava ao contexto da frase e completar a lacuna oralmente. A opção por trabalhar com o preenchimento de lacunas permitiu retirar a informação ortográfica do texto escrito, para não influenciar os participantes na pronúncia do rótico.
A pesquisa considerou as seguintes variáveis: língua (BP ou inglês-L2), origem geográfica do participante (Belo Horizonte ou Lavras), distribuição do rótico em contextos específicos (5 contextos em inglês-L2), grau de proficiência em inglês (básico ou avançado), item lexical (20 do inglês e 13 do PB) e indivíduo (16 participantes).

\section{Resultados}

Esta seção discute os resultados obtidos. Inicialmente serão discutidos os dados do PB para Belo Horizonte e Lavras. Depois serão avaliados os dados de inglês-L2. A análise do PB teve por objetivo avaliar três categorias específicas do rótico em final de sílaba: 1) aproximante retroflexa, 2) fricativa, 3) nenhum/outro segmento. Esta categorização foi feita de oitiva com suporte da visualização acústica do dado. O propósito desta etapa da pesquisa era verificar o tipo de rótico que os falantes de Belo Horizonte e de Lavras produziam em posição pós-vocálica para, posteriormente, avaliar a produção dos mesmos falantes em inglês-L2. O resultado geral dos dados do PB é apresentado na Tabela 1.

\begin{tabular}{|l|l|l|l|l|}
\cline { 2 - 5 } \multicolumn{1}{c|}{} & \multicolumn{2}{l|}{ Belo Horizonte } & \multicolumn{2}{l|}{ Lavras } \\
\hline $\begin{array}{l}\text { Aproximante } \\
\text { retroflexa }\end{array}$ & 0 & $0 \%$ & 102 & $98 \%$ \\
\hline Fricativa & 97 & $93,60 \%$ & 1 & $1 \%$ \\
\hline Outros & 7 & $6,40 \%$ & 1 & $1 \%$ \\
\hline TOTAL & 104 & & 104 & \\
\hline
\end{tabular}

Tabela 1: Róticos em posição pós-vocálica no PB

A Tabela 1 mostra que em posição pós-vocálica os falantes de Belo Horizonte realizaram o rótico como uma fricativa em 93,6\% dos casos. Nos 7 dados restantes, houve apagamento do rótico nas seguintes palavras: parque, carta, norte, porta, cor e dar. Os resultados apontam que em Belo Horizonte o rótico em posição pós-vocálica é recorrentemente uma fricativa, a qual pode, eventualmente, ser cancelada (OLIVEIRA, 1983, 1997; HUBACK, 2006). Já na cidade de Lavras a aproximante retroflexa em posição pós-vocálica ocorreu em $98 \%$ dos casos. Um dado foi produzido com a fricativa 
na palavra corta e outro dado foi produzido com a vocalização do rótico na palavra porta. Os resultados da cidade de Lavras apontam que em posição pós-vocálica o rótico é recorrentemente uma aproximante retroflexa.

Considerando-se os dados do PB retomamos a nossa pergunta de pesquisa: Como se dá a apropriação da aproximante retroflexa por aprendizes brasileiros de inglês-L2, levando em consideração diferentes variedades dialetais?

A partir da fundamentação teórica adotada, que é baseada nos Modelos Multirrepresentacionais, esperase que falantes de Lavras apresentem maiores índices de aproximantes retroflexas em inglês-L2 do que falantes de Belo Horizonte. Isto porque a aproximante retroflexa ocorre na variedade de Lavras, mas não ocorre na variedade de Belo Horizonte. Princípios de categorização seriam ativados e propiciariam aos falantes de Lavras a ativação da categoria da aproximante retroflexa em L2. O mesmo não ocorreria para falantes de Belo Horizonte, que não produzem a aproximante retroflexa em sua variedade dialetal. Considere a Tabela 2.

\begin{tabular}{|l|l|l|l|l|}
\hline & \multicolumn{2}{|l|}{ Belo Horizonte } & \multicolumn{2}{l|}{ Lavras } \\
\hline $\begin{array}{l}\text { Aproximante } \\
\text { retroflexa }\end{array}$ & 136 & $87 \%$ & 155 & $98,70 \%$ \\
\hline Fricativa & 16 & $10,20 \%$ & 1 & $0,65 \%$ \\
\hline Outros & 5 & $3,10 \%$ & 1 & $0,65 \%$ \\
\hline TOTAL & 157 & & 157 & \\
\hline
\end{tabular}

Qui-quadrado 17.14. $\mathrm{p}<0.0002$

Tabela 2: Róticos em posição final de sílaba em inglês-L2

A Tabela 2 apresenta os índices dos róticos atestados em inglês-L2 nas cidades de Belo Horizonte e de Lavras. ${ }^{15}$ Os resultados indicam que tanto falantes de Lavras $(98,70 \%)$ quanto falantes de Belo Horizonte (87\%) produzem a aproximante retroflexa em altos índices. Os dados de Lavras apontam para a quase categoricidade da ocorrência da aproximante retroflexa em posição pós-vocálica em inglês-L2 (98\%). A categoricidade da aproximante retroflexa em inglês-L2 de falantes de Lavras ocorreu não apenas em posição pós-vocálica, mas também em outros contextos distribucionais (cf. Quadro 2). Este resultado confirma a hipótese inicial de que o conhecimento de um som em L1 contribui para a sua apropriação em L2.

Contudo, os resultados obtidos para Belo Horizonte respondem de uma maneira não esperada à nossa pergunta de pesquisa. Isto porque esperávamos que falantes da variedade de Belo Horizonte apresentassem índices baixos de aproximantes retroflexas uma vez que este som não ocorre nesta variedade dialetal. Mas, o índice de aproximantes retroflexas obtido em nossos resultados foi de $87 \%$, que é bastante alto. O alto índice de aproximantes retroflexas na variedade de Belo Horizonte pode sugerir que o conhecimento perceptual contribui para a apropriação de sons de L2. Isto porque os falantes de Belo Horizonte, em princípio, têm conhecimento da pronúncia possível da aproximante retroflexa em posição pós-vocálica em variedades como a de Lavras (RENNICKE 2011). Contudo, como a pesquisa reportada neste artigo não avaliou aspectos perceptuais da aproximante retroflexa, esta proposta deve ser avaliada em estudos futuros.

Os Modelos Multirrepresentacionais nos permitem avaliar alguns aspectos que podem contribuir para a maior compreensão da apropriação dos róticos em inglês-L2 de falantes brasileiros. Pretendemos avaliar os contextos distribucionais, o item lexical específico, o grau de proficiência e o indivíduo. Os contextos distribucionais e o item léxico são fatores linguísticos e o grau de proficiência e o indivíduo são fatores extra-linguísticos. Os Modelos Multirrepresentacionais sugerem que fatores linguísticos e não linguísticos interagem na construção do conhecimento gramatical. A seguir serão considerados os resultados dos cinco contextos distribucionais em que a aproximante retroflexa ocorre em inglês-L2 dos falantes de Belo Horizonte. Considere a Tabela 3. 


\begin{tabular}{|l|l|l|l|l|l|l|l|l|l|l|}
\hline Rótico & \multicolumn{2}{l|l}{$\begin{array}{l}\text { posição } \\
\text { pós-vocálica } \\
\text { em final de } \\
\text { palavra }\end{array}$} & $\begin{array}{l}\text { posição pós- } \\
\text { vocálica seguida } \\
\text { de consoante }\end{array}$ & $\begin{array}{l}\text { posição pós-vocálica } \\
\text { seguida de vogal }\end{array}$ & \multicolumn{2}{l|}{ Início de palavra } & Encontro consonantal \\
\hline Aprox. retroflexa & 22 & $73,3 \%$ & 24 & $75 \%$ & 29 & $90,6 \%$ & 29 & $93,5 \%$ & 32 & $100 \%$ \\
\hline Fricativa & 7 & $23,3 \%$ & 7 & $21,8 \%$ & 0 & $0 \%$ & 2 & $6,5 \%$ & 0 & $0 \%$ \\
\hline Outros & 1 & $3,4 \%$ & 1 & $3,2 \%$ & 3 & $9,4 \%$ & 0 & $0 \%$ & 0 & $0 \%$ \\
\hline TOTAL & 30 & & 32 & & 32 & & 31 & & 32 & \\
\hline
\end{tabular}

Qui-quadrado 24.18. $\mathrm{p}<0.0002$

Tabela 3: Róticos em em inglês-L2 de falantes de Belo Horizonte, por contextos distribucionais

A Tabela 3 mostra que a realização da aproximante retroflexa em encontro consonantal foi categórica em inglês-L2 de falantes de Belo Horizonte (100\%). Alto índice de aproximantes retroflexas ocorreu em início de palavra $(93,5 \%)$ e em posição pós-vocálica seguida de vogal (90,6\%). Por outro lado, em posição pósvocálica em final de palavra a aproximante retroflexa ocorreu em 73,3\% dos casos e em posição pós-vocálica seguida de consoante a aproximante retroflexa ocorreu em $75 \%$ dos casos. Observa-se que a pós-vocálica tem comportamento distinto quando seguido de vogal - com índices de 90,6\% - e em pós-vocálica em final de palavra - 73,3\% dos casos - ou em pós-vocálica se- guida de consoante - $75 \%$ dos casos. Entendemos que este resultado expressa que contextos aparentemente semelhantes - a posição pós-vocálica - podem apresentar comportamento distinto dependendo do contexto global adjacente (que segue ou precede, ou padrão acentual etc.). Esta interpretação é compatível com os Modelos Multirrepresentacionais que sugerem que o conhecimento gramatical incorpora o detalhe fonético. Os Modelos Multirrepresentacionais também sugerem que o léxico tenha estreita relação com o conhecimento gramatical e, neste sentido, será avaliado em seguida, o comportamento dos itens léxicos particulares. Considere a Tabela 4:

\begin{tabular}{|c|c|c|c|c|c|c|c|c|}
\hline \multirow{5}{*}{$\begin{array}{l}\text { Grupo e } \\
\text { Contexto } \\
\text { Grupo 1: posição pós- } \\
\text { vocálica em final de } \\
\text { palavra }\end{array}$} & \multirow[b]{2}{*}{1} & \multirow{2}{*}{ 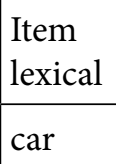 } & \multicolumn{2}{|c|}{$\begin{array}{l}\text { Aproximante } \\
\text { retroflexa }\end{array}$} & \multicolumn{2}{|c|}{ Fricativa } & \multicolumn{2}{|c|}{ Outros } \\
\hline & & & 4 & $57 \%$ & 2 & $28 \%$ & 1 & $15 \%$ \\
\hline & 2 & far & 5 & $71 \%$ & 2 & $29 \%$ & 0 & 0 \\
\hline & 3 & door & 6 & $75 \%$ & 2 & $25 \%$ & 0 & 0 \\
\hline & 4 & four & 7 & $87 \%$ & 1 & $13 \%$ & 0 & 0 \\
\hline & 5 & kart & 7 & $87 \%$ & 1 & $13 \%$ & 0 & 0 \\
\hline Grupo 2: posição pós- & 6 & heart & 5 & $62 \%$ & 3 & $38 \%$ & 0 & 0 \\
\hline vocálica + C & 7 & fork & 6 & $75 \%$ & 2 & $25 \%$ & 0 & 0 \\
\hline & 8 & short & 6 & $75 \%$ & 1 & $12,5 \%$ & 1 & $12,5 \%$ \\
\hline & 9 & zero & 6 & $75 \%$ & 0 & 0 & 2 & $25 \%$ \\
\hline Grupo 3: posição pós- & 10 & merry & 7 & $87 \%$ & 0 & 0 & 1 & $13 \%$ \\
\hline vocálica $+\mathrm{V}$ & 11 & story & 8 & $100 \%$ & 0 & 0 & 0 & 0 \\
\hline & 12 & sorry & 8 & $100 \%$ & 0 & 0 & 0 & 0 \\
\hline
\end{tabular}




\begin{tabular}{|l|l|l|l|l|l|l|l|l|}
\hline \multirow{4}{*}{$\begin{array}{l}\text { Grupo 4: Início de } \\
\text { palavra }\end{array}$} & 13 & red & 6 & $75 \%$ & 2 & $25 \%$ & 0 & 0 \\
\cline { 2 - 9 } & 14 & rock & 7 & $100 \%$ & 0 & 0 & 0 & 0 \\
\cline { 2 - 9 } & 15 & read & 8 & $100 \%$ & 0 & 0 & 0 & 0 \\
\hline \multirow{4}{*}{$\begin{array}{l}\text { Grupo 5: encontro } \\
\text { consonantal }\end{array}$} & 16 & roof & 8 & $100 \%$ & 0 & 0 & 0 & 0 \\
\cline { 2 - 9 } & 17 & fruit & 8 & $100 \%$ & 0 & 0 & 0 & 0 \\
\cline { 2 - 9 } & 18 & price & 8 & $100 \%$ & 0 & 0 & 0 & 0 \\
\cline { 2 - 9 } & 20 & gread & 8 & $100 \%$ & 0 & 0 & 0 & 0 \\
\hline
\end{tabular}

Tabela 4: Ocorrência de róticos por item lexical para falantes de inglês-L2 de Belo Horizonte

A finalidade de analisar itens lexicais específicos é a de verificar se eles se comportam de maneira análoga ou distinta, dentro de seu contexto distribucional. Os Modelos Multirrepresentacionais sugerem que itens lexicais podem ter comportamentos distintos mesmo tendo contextos distribucionais semelhantes. A Tabela 4 mostra que a realização da aproximante retroflexa somente é categórica entre os itens lexicais com um encontro consonantal (Grupo 5). Observamos também que no Grupo 4, em início de palavra, a palavra red (vermelho) apresenta $75 \%$ de realização da aproximante retroflexa e $25 \%$ de realização da fricativa, diferente dos outros itens no mesmo contexto, os quais apresentaram $100 \%$ de aproximantes retroflexas. Nos demais contextos, observamos variação entre $57 \%$ e $87 \%$ na produção da aproximantes retroflexas entre os itens lexicais.

No Grupo 3 a aproximante retroflexa apresentou duas ocorrências de tepe (na palavra zero) e uma ocorrência de cancelamento (na palavra merry). No Grupo 1 (posição pós-vocálica em final de palavra) e no Grupo 2 (posição pós-vocálica seguida de consoante), observou-se que em todos os itens léxicos a aproximante retroflexa foi substituída por fricativas e os outros casos envolveram o cancelamento ( 2 casos). Sugerimos que esses resultados indicam não apenas que a apropriação da aproximante retroflexa por aprendizes brasileiros de inglês-L2 depende do item lexical, mas que o contexto de posição pós-vocálica apresenta desafios para os aprendizes brasileiros de inglês-L2.

A apropriação da aproximante retroflexa em índice menor na posição pós-vocálica pode estar relacionada com o fato de que é exatamente neste contexto que ocorre variação entre os róticos no $\mathrm{PB}$. A variação atestada entre a aproximante retroflexa e a fricativa em dados de inglês-L2 é similar, em termos de contexto distribucional, àquela encontrada em L1: posição pós-vocálica (cf. Quadro 1). Este resultado indica que aspectos da variação em L1 podem ser transpostos para L2. A variação, portanto, é compreendida como parte da representação linguística e pode ser associada a itens lexicais específicos.

De acordo com os Modelos Multirrepresentacionais fatores não linguísticos também têm impacto na organização do conhecimento linguístico. Nas próximas páginas exploraremos o nível de proficiência e o indivíduo (aprendiz) visando compreender melhor o fenômeno estudado. Os dados refletem resultados de Belo Horizonte, uma vez que esta variedade dialetal apresentou variação dos róticos em inglês-L2, enquanto a cidade de Lavras apresentou índices quase categóricos da aproximante retroflexa em inglês-L2 (cf. Tabela 2). Considere a Tabela 5.

\begin{tabular}{|l|l|l|l|l|}
\hline Rótico & \multicolumn{2}{|l|}{ Básico } & \multicolumn{2}{l|}{ Avançado } \\
\hline $\begin{array}{l}\text { Aproximante } \\
\text { retroflexa }\end{array}$ & 58 & $74,3 \%$ & 78 & $98,7 \%$ \\
\hline Fricativa & 16 & $20,5 \%$ & 0 & $0 \%$ \\
\hline Outros & 4 & $5,2 \%$ & 1 & $1,3 \%$ \\
\hline TOTAL & 114 & & 79 & \\
\hline
\end{tabular}

Qui-quadrado 18.69. $\mathrm{p}<0.0001$

Tabela 5: Ocorrência de róticos em inglês-L2 por nível de proficiência na variedade de Belo Horizonte 
A Tabela 5 indica que os falantes de Belo Horizonte, aprendizes inglês-L2 do nível básico, realizam a aproximante retroflexa em $74,3 \%$ dos dados e a fricativa em $20,5 \%$ dos dados. Por outro lado, os aprendizes de Belo Horizonte do nível avançado de inglês-L2 não realizaram a fricativa em nenhum dado, ou seja, a aproximante retroflexa foi produzida categoricamente. Esses resultados indicam que o maior tempo de aprendizagem de L2 implica a maior realização da aproximante retroflexa. A partir do que foi analisado, até então, os dados mostram que a aproximante retroflexa é adquirida rapidamente no inglês-L2 com índices altos, independente da variedade dialetal. Contudo, são os aprendizes do nível básico de inglês que apresentam a aproximante retroflexa em competição com a fricativa e outros casos.

De acordo com Larsen-Freeman (2006) trajetórias individuais possíveis ocorrem no aprendizado de L2. Ou seja, independente do tempo dispendido pelos indivíduos no aprendizado de L2 é possível observar características particulares que emergem em âmbito individual. ${ }^{16}$ Assim, consideramos o comportamento dos indivíduos do nível básico de proficiência, uma vez que os indivíduos do nível avançado de proficiência apresentam realização quase categórica da aproximante retroflexa. Pretendemos avaliar se os indivíduos agrupados em um mesmo nível de proficiência se comportam de maneira análoga ou diferente no que diz respeito à realização da aproximante retroflexa. Considere a Tabela 6.

\begin{tabular}{|l|l|l|l|l|l|l|}
\hline Participantes & \multicolumn{2}{|l|}{$\begin{array}{l}\text { Aproximante } \\
\text { retroflexa }\end{array}$} & \multicolumn{2}{l|}{ Fricativa } & \multicolumn{2}{l|}{ Outros } \\
\hline Participante 1-Básico & 12 & $60 \%$ & 6 & $30 \%$ & 2 & $10 \%$ \\
\hline Participante 2-Básico & 20 & $100 \%$ & 0 & 0 & 0 & 0 \\
\hline Participante 3-Básico & 12 & $60 \%$ & 8 & $40 \%$ & 0 & 0 \\
\hline Participante 4-Básico & 14 & $78 \%$ & 2 & $11 \%$ & 2 & $11 \%$ \\
\hline
\end{tabular}

Tabela 6: Realização de róticos em inglês-L2, por indivíduo do nível básico, de falantes de Belo Horizonte

A Tabela 6 apresenta dados de falantes de Belo Horizonte, do nível básico de inglês-L2. Apesar do nível básico como um todo apresentar índice elevado na produção da aproximante retroflexa $(74,5 \%)$, nem todos os indivíduos produziram esse som em altos índices. $\mathrm{O}$ participante 2-Básico produziu todos os róticos como aproximantes retroflexas (100\%). Por outro lado, os participantes 1 e 3-Básico produziram a aproximante retroflexa em $60 \%$ dos casos esperados. Para o participante 1-Básico, nos casos em que a aproximante retroflexa não ocorreu, foi observado que a fricativa ocorreu em 30\% dos dados e outros casos apresentaram índice de 10\%. Por outro lado, para o participante 3-Básico, nos casos em que a aproximante retroflexa não ocorreu, foi observado somente a fricativa em competição (40\%). O participante 4-Básico apresentou 78\% de aproximantes retroflexas, $11 \%$ de fricativas e $11 \%$ de outros casos. Esses resultados indicam que a aproximante retroflexa ocorre em altos índices no nível básico, mas essa ocorrência é diferenciada entre os indivíduos. Ou seja, indivíduos têm percursos individuais na construção de L2.

\section{Conclusão}

Este artigo pretendeu ser uma contribuição sobre fatores que, aparentemente, não impõem desafios ao estudante de L2. O foco foi na apropriação da aproximante retroflexa em inglês-L2 de falantes brasileiros. Observou-se que a aproximante retroflexa ocorre em altos índices no inglês-L2 de falantes do português brasileiro, mesmo em níveis iniciais de aprendizagem. Foi avaliada a hipótese de que sons similares em L1 e L2 são categorizados mais prontamente do que sons de L2 que são desconhecidos em L1. Assim, esperavase que falantes de uma variedade com a aproximante retroflexa em L1 teriam índices maiores da aproximante retroflexa em inglês-L2 do que falantes cuja variedade não apresentasse a aproximante retroflexa. Curiosamente, os índices para as duas variedades foram semelhantes. Este resultado nos leva a postular que o conhecimento perceptual pode contribuir para a apropriação de sons de L2. Isto porque os falantes de Belo Horizonte, em princípio, têm conhecimento da pronúncia possível da aproximante retroflexa em posição pós-vocálica em variedades como a de Lavras (RENNICKE 2011). Contudo, como o estudo apresentado neste artigo não avaliou aspectos perceptuais da aproximante retroflexa, esta proposta deve ser avaliada em estudos futuros. 
Neste artigo exploramos o comportamento de itens lexicais específicos (cf. Tabela 4). Os resultados indicaram não apenas que a apropriação da aproximante retroflexa por aprendizes brasileiros de inglês-L2 depende do item lexical, mas que os contextos de posição pós-vocálica em final de palavra e de pós-vocálica seguida de consoante apresentam maiores desafios para os aprendizes brasileiros de inglês-L2. A dificuldade de apropriação da aproximante retroflexa nestes contextos pode estar relacionada com o fato de que é exatamente em pós-vocálica em final de palavra e de pós-vocálica seguida de consoante que ocorre variação entre os róticos no $\mathrm{PB}$.

Consideramos também o tempo de exposição à L2. Aprendizes de nível avançado apresentam maiores índices de aproximantes retroflexas do que aprendizes de nível básico. Este resultado corrobora princípios dos Modelos Multirrepresentacionais que assumem que o tempo é crucial na consolidação do conhecimento gramatical. Indivíduos têm trajetórias individuais de conhecimento gramatical seja em L2 ou L1.

Uma linha de investigação em pesquisas futuras poderia avaliar quais itens lexicais tendem a não apresentar a aproximante retroflexa. Camargos (2013) sugere que palavras cognatas têm comportamento fonológico diferente de palavras não cognatas. Segundo o autor as palavras cognatas apresentam menores índices de aproximantes retroflexas do que outras palavras. Este resultado amplia a discussão sobre a variação estar presente na representação linguística uma vez que palavras cognatas compartilham propriedades semânticas, além de propriedades fonológicas.

Outra linha de investigação a ser empreendida em estudos futuros deve considerar o papel do conhecimento perceptual na apropriação de inglês-L2. Os resultados apresentados neste artigo permitem sugerir que sons de L2 que sejam perceptualmente salientes em L1 podem ser produzidos com menor desafio do que sons que sejam desconhecidos para os falantes de L1. Nesta perspectiva espera-se que falantes de L1 que possam reproduzir variantes diferentes da sua sejam capazes de se apropriar destes sons em L2 com desafios menores.

Uma contribuição importante deste artigo é identificar que a apropriação da aproximante retroflexa em inglês-L2 atinge excelentes níveis em inglês-L2 de falantes brasileiros em todos os níveis de proficiência. Assim, o foco no ensino de pronúncia do inglês não necessita ser explicitamente na apropriação do rótico, uma vez que mesmo sem treinamento específico a aproximante retroflexa apresenta altos índices de realização em inglês -L2 de falantes brasileiros. Embora a aproximante retroflexa seja apropriada em níveis iniciais de inglês-L2, há fatores como o tempo de estudo, o aprendiz ou o item lexical em questão, que são relevantes para consolidar L2. Estes resultados apontam para o ensino de L2 a partir de propriedades gramaticais específicas de L1 e com relação a elementos não linguísticos (o tempo de estudo ou o indivíduo). De fato, as evidências apresentadas neste artigo indicam que o conhecimento gramatical é um construto dinâmico, entrelaçado por vários fatores e incorpora informações linguísticas e não linguísticas.

\section{Notas}

1. Os autores agradecem ao apoio do $\mathrm{CNPq} 30.65 .95 / 2011$ 7 e da FAPEMIG PPM-00399-14 para a realização da pesquisa refletida neste artigo. Os autores agradecem, adicionalmente, aos pareceristas que avaliaram o artigo, por seus comentários e sugestões.

2. Apesar de alguns autores estabelecerem a diferença entre os termos "segunda língua" (L2) e "língua estrangeira" (LE), neste artigo assumimos que os dois termos têm equivalência semântica. Para discussão específica sobre este tema veja Stern (1983). Este artigo reflete parte dos resultados apresentados em Camargos (2013).

3. Há também o conhecimento declarativo ou proposicional em que o falante é capaz de explicitar, por exemplo, o significado das palavras.

4. Um ponto final é utilizado para indicar o limite entre sílabas.

5. No PB, em final de sílaba, o rótico pode também ocorrer como outras fricativas posteriores, pode também ser cancelado ou pode ocorrer como um tepe. Limitamos a discussão neste artigo entre a fricativa glotal e a aproximante retroflexa de maneira a focar no tema proposto: a apropriação de róticos em inglês L2 de falantes mineiros.

6. A literatura adota várias denominações para os róticos em inglês: aproximante (LADEFOGED, 1975), aproximante retroflexa (ROACH, 2009), constritiva (ABERCROMBIE, 1967). Neste artigo adotamos a nomenclatura aproximante retroflexa para referir ao rótico do inglês e este será representado por [r] como 
é tipicamente adotado na literatura (DELATTRE \& FREEMAN, 1968; LADEFOGED, 1975).

7. Tipicamente o inglês britânico é caracterizado como não-rótico e o inglês americano é caracterizado como rótico. Há, contudo, falares róticos e não-róticos nas duas variedades.

8. Róticos em posição inicial no inglês L2 de falantes brasileiros foram estudados por Schadech (2013).

9. No PB pode ocorrer o cancelamento do rótico pósvocálico que é recorrente em formas verbais no infinitivo: cantar > cantá. Este aspecto do $\mathrm{PB}$ não é relevante para a discussão apresentada neste artigo que tem por objetivo avaliar a apropriação de róticos em inglês L2 de falantes brasileiros, e não o cancelamento de róticos.

10. A Fonologia de Uso supõe que efeitos de frequência são importantes para a organização do conhecimento fonológico. Contudo, como este tema não é relevante para o foco central deste artigo, optou-se por não incorporá-lo à discussão.

11. Aprovação do Comitê de Ética em Pesquisa CAAE 07679112.3.0000.5149.

12. A cidade de Belo Horizonte é a capital do estado de Minas Gerais e conta com aproximadamente 2.400.000 habitantes (Censo IBGE-2010). A cidade de Lavras está localizada no sul do estado de Minas Gerais, distando aproximadamente $240 \mathrm{~km}$ de Belo Horizonte. A cidade conta com 92.200 habitantes (Censo IBGE-2010). Os autores agradecem à professora Raquel Fontes Martins, da Universidade Federal de Lavras, pelo apoio logístico e institucional no desenvolvimento da pesquisa.

13. Participantes com nível básico de proficiência tiveram de 6 meses a 1 ano de estudo contínuo da língua inglesa. Participantes com nível avançado de proficiência tiveram no mínimo 3 anos de estudo contínuo da língua inglesa.

14. Os 13 itens léxicos do português foram classificados em dois grupos e são: Grupo 1-Final de palavra: bar, par, dar, cor, dor; Grupo 2-Meio de palavra: carta, barco, parto, porta, corta, parque, parte, norte. $\mathrm{O}$ inglês contou com 20 itens léxicos classificados em cinco grupos: Grupo 1-final de sílaba e de palavra: car, far, door, four; Grupo 2-Final de sílaba seguida de consoante: kart, heart, fork, short; Grupo 3-Final de sílaba seguida de vogal: zero, merry, story, sorry; Grupo 4-Início de palavra: red, rock, read, roof; Grupo 5-Encontro consonantal: fruit, price, bread, grape. Camargos (2013) analisou também um grupo de palavras denominadas quase-homófonas. A classe de itens lexicais quase-homófonos consistiu de: bar/bar, parque/park, parte/part, norte/North.O autor sugeriu que neste grupo de palavras há forte consolidação das representações e, por esta razão, este grupo de palavras tem comportamento diferenciado. Por limitações de espaço este tema não poderá ser discutido neste artigo.

15. Os dados esperados totalizaram 160 itens (20 palavras $\mathrm{x}$ 16 participantes). Entretanto, 6 dados foram excluídos, devido a ruídos externos ou não foram pronunciados.

16. No caso analisado neste artigo o elemento de análise é a aproximante retroflexa. A expectativa de particularidades individuais é esperada para todo e qualquer nível de análise.

\section{Referências}

ABERCROMBIE, David. Elements of General Phonetics. Edinburgh: Edinburgh University Press, 1967. 203p.

ANDERSON, John R. Rules of the mind. Hillsdale, NJ: Erlbaum.1993.

BARLOW, Michael; KEMMER, Suzanne. Usage-based models of language. Stanford: CSLI, 2000. 384p.

BOD, Rens; COCHRAN, David. Introduction to Exemplar-Based Models. In: R. Bod \& D. Cochran (Ed.). Proceedings ESSLLI worshop "Exemplar-Based Models of Language Acquisition and Use. 2007.

BRANDÃO, Silvia Figueiredo. Nas trilhas do retroflexo. Signum: Estudos de Linguagem, Londrina: UEL. v.10(2): 265-283, dez. 2007.

BYBEE, Joan. Phonology and Language Use. Cambridge: Cambridge University Press, 2001. 260p.

Usage-based grammar and second language acquisition. In: ROBINSON, Peter; ELLIS, Nick (Ed.). Handbook of Cognitive Linguistics and Second Language Acquisition. New York: Routledge, 2008. p. 216-236.

Language, Usage and Cognition. Cambridge: Cambridge University Press, 2010.

CAMARGOS, Marco Aurélio Cunha. Conhecimento Fonológico de Retroflexos em inglês-L2. 2013. 104f. Dissertação (Mestrado em Estudos Linguísticos). Faculdade de Letras, Universidade Federal de Minas Gerais, Belo Horizonte, 2013.

CRISTÓFARO-SILVA, Thaïs. Fonética e Fonologia do Português: roteiro de estudos e guia de exercícios. São Paulo: Contexto, 1999.

DELATTRE, Pierre; FREEMAN, Donald. A dialect study of American's r's by $\mathrm{x}$-ray motion picture. Linguistics: An International Review. 44, 29-68, 1968.

ELLIS, Nick. Constructions, chunking, and connectionism: The emergence of second language structure. In: DOUGHTY, Catherine; LONG, Michael (Ed.). 
Handbook of second language acquisition. Oxford: Blackwell, p. 33-68. 2003.

HUBACK, Ana Paula da Silva. Cancelamento do (r) final em nominais: uma abordagem difusionista. SCRIPTA, Belo Horizonte, v.9, n.18, p.11-28, 2006.

JOHNSON, Keith. Speech perception without speaker normalization. In: JOHNSON, Keith; MULLENNIX, John (Ed). Talker variability in speech processing. San Diego: Academic Press, 1997.

LADEFOGED, Peter. A Course in Phonetics. Harcourt Brace Jovanovich, Inc., 1975.

LADEFOGED, Peter; MADDIESON, Ian. The sounds of the world's languages. Cambridge: Blackwell, 1996.

LARSEN-FREEMAN, Diane. The emergence of complexity, fluency, and accuracy in the oral and written production of five Chinese learners of English. Applied Linguistics, Oxford University, v. 27.4, p. 590619, jul. 2006.

LINDAU, Mona. The story of /r/. In: FROMKIN, Victoria (Org), V. Phonetic Linguistics: Essays in Honor of Peter Ladefoged (edited by Victoria Fromkin). New York: Academic Press, 1985.

MAGNUSON, Thomas. The story of $/ \mathrm{r} /$ in two vocal tracts. Proceedings 16th International Congress of the Phonetic Sciences. Germany, 2007.

OLIVEIRA, Marco Antônio de. Phonological variation and change in Brazilian Portuguese: the case of the liquids. 1983. 270f. Tese (Doutorado em Linguística) University of Pennsylvania, Philadelphia, 1983.

Reanalisando o processo de cancelamento do (r) em final de sílaba. Revista de Estudos da Linguagem, Belo Horizonte, v. 6, n. 2, p. 31-58. jul./dez. 1997.

PIERREHUMBERT, Janet. Exemplar dynamics: Word frequency, lenition and contrast. In. BYBEE, Joan \& HOPPER Paul. (Ed). Frequency and the emergency of linguistic structure. Amsterdam: John Benjamins, 2001.

Probabilistic phonology: discrimination and robustness. In: BOD, Rens, HAY, Jennifer (Ed). Probabilistic linguistics, MIT Press, 2003.

RENNICKE, Iiris Emilia. The retroflex $r$ of Brazilian Portuguese: theories of origin and a case study of language attitudes in Minas Gerais. In: Linguística: Revista de Estudos Linguísticos da Universidade do Porto. Porto, v. 6, n. 1. 2011.

ROACH, Peter. English phonetics and phonology: glossary. Fourth Edition, Cambridge University Press, 2009.
ROBINSON, Peter; ELLIS, Nick. (Eds.). Handbook of Cognitive Linguistics and Second Language Acquisition. New York/London : Routledge, 2008.

SCHADECH, Thais Suzana. The production of wordinitial $/ \mathrm{x} /$ by Brazilian learners of English and the issues of comprehensibility and intelligibility. Dissertação de Mestrado. Universidade Federal de Santa Catarina. 2013.

STERN, Hans Heinrich. Fundamental concepts of language teaching. Oxford: Oxford University Press, 1983.

Recebido em: 21/09/2015 Aceito em: 29/11/2015 